\title{
Fluorine F 18 Alfatide II
}

National Cancer Institute

\section{Source}

National Cancer Institute. Fluorine F18 Alfatide II. NCI Thesaurus. Code C121959.

A radiotracer composed of a pegylated, dimeric arg inine-glycine-aspartic acid (RGD) peptide (PRGD2), radiolabeled, via the chelating agent 1,4,7-triazacyclononane- $N, N^{\prime}, N "$ triacetic acid (NOTA), to a fluorine F 18-aluminum complex (AIF), with potential alphaVbeta3 integrin (vitronectin receptor) imaging activity using positron emission topog raphy (PET). Upon administration, the RGD moiety of fluorine F 18 alfatide II selectively binds to alphaVbeta3 integrin. During PET, alphaVbeta3-expressing tumor cells can be visualized and the degree of tumor angiogenesis can be determined. AlphaVbeta3 integ rin, a cell adhesion and signaling receptor, is upregulated in tumor vessel endothelial cells and has been associated with neovascularization, differentiation, proliferation of tumor cells, and metastasis. Pegylation provides improved drug penetration into tumors and decreases drug clearance, thereby increasing efficacy while lowering systemic toxicity. 